\title{
Los presos políticos del penal de Rawson: un tratamiento para la desubjetivación Argentina (1970-1980)
}

Débora D'Antonio*

Resumen: El penal de Rawson ubicado en la provincia de Chubut en la Patagonia argentina se erigió como una prisión singular dentro de la red de penales donde fueron alojados los presos políticos durante las dictaduras de los años sesenta y setenta. Allí se ejercitó una tecnología de disciplinamiento fundada en una variedad de tormentos manifiestamente anticonstitucionales y alejados de los marcos normativos estipulados para el funcionamiento del sistema penitenciario. En este texto nos proponemos demostrar a través de una interpretación de género, que si bien el objetivo explícito del régimen militar al quebrar la subjetividad de los presos fue la destrucción ideológica y política de los mismos, este proceso se consumó en términos de una lógica de género desmasculinizadora que contradecía la retórica que en torno a la masculinidad ensayaron públicamente, tanto militares como penitenciarios, poniendo de manifiesto que no había coherencia entre el discurso público de género de corte familiarista y las prácticas de disciplinamiento que se ensayaban en los espacios de encierro.

Palabras claves: Presos políticos. Represión. Desubjetivación. Desmasculinización.

* Doctora en Historia por la Universidad de Buenos Aires, investigadora del Instituto Interdisciplinario de Estudios de Género de la Facultad de Filosofía y Letras y profesora en la misma institución. 


\section{Introducción}

Desde mediados de los años cincuenta se produjo en la Argentina una profunda crisis de dominación política. La proscripción del peronismo, el movimiento de mayor influjo popular, y el establecimiento casi sin pausa del intervencionismo militar, condicionaron la posibilidad de que alguno de los sectores en disputa asumiera la dirección institucional de la sociedad, en un marco donde los diferentes proyectos de los principales factores de poder quedaban impugnados por sus rivales, sin que ninguno pudiera presentar sus propios intereses como los del conjunto social.

Este virtual "empate” entre las fuerzas sociales -según la clásica caracterización de Juan Carlos Portantiero (1977) intentó ser resuelto por el golpe de Estado liderado por el general Juan Carlos Onganía en 1966, sobre la base de un acuerdo que sentó garantías comunes para los contendientes, esto es: el reforzamiento del Estado por medio de la utilización cada vez más frecuente de sus aparatos de represión, espionaje y control. ${ }^{1}$ Así, las distintas administraciones civiles y militares que se sucedieron desde 1955 por casi veinte años, con contadas excepciones, afinaron la calidad y la capacidad de acción de los aparatos de seguridad y control social, especializándolos, en ocasiones, al ritmo de una creciente beligerancia social.

A fines de los años sesenta y comienzos de los años setenta, las instituciones para la vigilancia y el castigo tuvieron en la mira a la protesta obrera y estudiantil, la actividad de las organizaciones de la izquierda y el peronismo revolucionario y, particularmente, a aquellas de carácter político-militar. De este modo quedó expuesta una nueva relación entre los aparatos represivos y una legislación adecuada para encorsetar el ascenso en la lucha de clases y la amplificación de las nuevas costumbres culturales, expresadas en la liberación sexual, el consumo de música beat o la utilización de drogas experimentales, que desairaban la perspectiva católica, integrista y retrógrada de los militares en el gobierno. No se trató de una modificación aislada sino de una creciente institucionalización de la violencia por parte de un Estado que había proscripto a los partidos políticos, intervenido la universidad pública e impuesto silencio e intimidación a las formas insumisas de activismo sindical. 
La creciente penetración del Estado autoritario sobre la sociedad civil tuvo como corolario una transformación profunda de los penales federales y provinciales. Algunos se crearon y otros se jerarquizaron. Esto último sucedió con el Servicio Penitenciario Federal (SPF), que tuvo una puesta en valor, fundamentalmente a través de una creciente especialización de las prisiones bajo su jurisdicción. Numerosas prisiones fueron refundadas como aparatos de control político dirigidos centralmente contra los sectores que resistían el orden social como la clase trabajadora, la juventud, el estudiantado y algunos sectores que abrazaban la lucha político-armada.

El sistema penitenciario nacional se renovó por medio de una unidad inusitada y las cárceles fueron conformando poco a poco un frente más de combate contra la "subversión". 2

En el contexto de la Guerra Fría y siguiendo tendencias internacionales, los militares argentinos, con el apoyo logístico-intelectual del Departamento de Estado Norteamericano y sobre la base de una alianza local que involucraba a una amplia gama de sectores de elite, aprobaron una serie de reglamentaciones que postulaban la centralidad del enemigo interno y la guerra no convencional. ${ }^{3}$ Hasta ese momento y antes de ser permeadas por las orientaciones generales de la Doctrina de Seguridad Nacional (DSN), que fue el sostén ideológico de las fuerzas de seguridad para justificar la persecución del "enemigo interno", las diversas cárceles del país constituían una red heterogénea.

La articulación del espacio en función del control social interno había estado sujeta a grandes variaciones regionales y la disciplina era regulada por reglamentos penitenciarios que, a pesar de los esfuerzos de las distintas administraciones, no habían podido ser estandarizados a escala nacional y se mantenían en tensión con normativas e instrucciones provinciales. El creciente interés depositado por las Fuerzas Armadas en el sistema penitenciario transformó los procedimientos requeridos respecto del trato al enemigo "subversivo". La iniciativa en la acción, las operaciones de inteligencia y el quiebre psicológico fueron algunos de los componentes con los que las fuerzas armadas exhortaban al resto de las fuerzas de seguridad para el manejo de los detenidos políticos. 


\section{Violencia y transformaciones penitenciarias}

Durante este período histórico de importante movilización y organización popular, el eje de la prisión dejó de ser la captura de quienes operaban en el mundo del delito por medio de robos contra la propiedad, estafas, tráfico ilegal, prostitución o crímenes de diversa índole, como decíamos, para colocar el foco en la persecución al activismo político y social. Si bien el sistema penitenciario desde muy tempranamente había destinado un lugar dentro de su agenda a la represión de los opositores, lo que se convierte en una novedad desde fines de la década del 60 , es el redoblamiento de este rol a partir del fuerte ascenso del conflicto social y la contribución directa desde mediados de la década siguiente, con las fuerzas armadas.

En esta nueva etapa en que la prisión argentina comenzó a formar parte de este sistema represivo cada vez más centralizado, la recuperación de los delincuentes se implantó de un modo diferente al que estableció la narrativa foucaultiana. La violencia no sólo no decreció, sino que jugó un rol fundamental en esa profundización de las transformaciones carcelarias. Hasta fines de los años sesenta las cárceles habían funcionado con un criterio ortopédico que tenía por fin devolver a la persona detenida a la sociedad mediante la inversión de los aspectos subjetivos que se delimitaban contrarios a una sociabilidad legal. De este modo, la reforma de la persona delincuente se llevaba a cabo a través del trabajo, el deporte y cierto bienestar material y psicológico en el encierro. Sin embargo, a partir del advenimiento del ciclo de dictaduras de mediados de años sesenta y sobre todo desde comienzos de los años setenta, ya no se dispuso de un espacio para la rehabilitación y reforma de los sujetos caracterizados de subversivos, tal como sí lo había pretendido y puesto en práctica el sistema penitenciario en la primera mitad del siglo XX para el delincuente común. ${ }^{4}$ 


\section{Maltratos carcelarios a comienzos de los años setenta}

El penal de Rawson, en la provincia de Chubut, fue junto al de Resistencia, en el Chaco, uno de los centros de reclusión que tras el levantamiento popular del Cordobazo de 1969 y el Viborazo en la misma provincia en 1971, concentró a un importante número de presos políticos y gremiales. En él fueron confinados gran cantidad de obreros que habían participado en las huelgas y asambleas organizadas por los sindicatos que lideraron estas jornadas. También fueron reunidos allí los militantes de las organizaciones armadas revolucionarias que a partir de 1970 comenzaron a tener mayor visibilidad y actuación pública.

En agosto de 1970 el penal de Rawson fue transformado en Instituto de Seguridad y Resocialización para el tratamiento de los condenados de máxima seguridad. A comienzos de esta década, ya contaba con un total de ocho pabellones de los cuales seis estaban ocupados por detenidos políticos. La población de presos osciló, según los años, entre unos 240 a $300 .^{5}$ A partir del gobierno de facto del general Alejandro Lanusse (1971-1973), la mitad de los prisioneros políticos existentes en el país fueron trasladados y centralizados en el penal patagónico lo que lo convirtió en un penal arquetípico de reclusión de los presos político. De modo tal que el predio fue ampliándose perimetralmente al calor de la insurgencia social y política del país y estuvo colmado durante el período que va desde el Cordobazo hasta la liberación masiva de presos y presas políticos en mayo de 1973.

Lanusse, reforzando la militarización de la institución, especificó por decreto que el Comando en Jefe del Ejército, asumiría el control operacional del penal de Rawson, asignado por el Comando en Jefe de la Armada como lugar de reclusión para presas y presos políticos. Esta medida respondía a un intento por parte del gobierno militar de evitar las fugas de las cárceles nacionales. Una resolución que tuvo lugar en el marco del éxito de varios escapes de presos y presas políticos de distintas cárceles provinciales, en junio del año 1971. Si bien las fugas no fueron masivas, pusieron en evidencia la vulnerabilidad y fragilidad de estas instituciones para el manejo de las presas y presos políticos. 
Cuando en abril de 1972 se aprobó el régimen para personas sometidas a proceso por la Cámara Federal en lo Penal, un tribunal creado para juzgar céleremente a los acusados de "subversivos/ as", comenzaron a deteriorarse fuertemente las condiciones de vida carcelarias. Lo primero que sucedió es que los presos quedaron incomunicados con el exterior y entre sí. Sin diarios, libros ni revistas, debían permanecer encerrados en sus celdas de 6 metros cuadrados todo el día con apenas un recreo de 40 minutos. Los calabozos, por otro lado, no tenían muebles y contaban con un camastro y una bacinilla para las necesidades fisiológicas que era vaciada solo una vez por día, por lo que el resto del tiempo, los presos debían convivir con el olor de los excrementos y la orina. ${ }^{6}$

Tras la caída de Cámpora en julio de 1973, sobrevino una aguda represión. Primero de la mano del gobierno interino de Raúl Lastiri, que duró apenas unos tres meses, y posteriormente del flamante gobierno del general Perón y su esposa. En esa ocasión el penal volvió a recibir presos políticos y apuntó en torno al tratamiento, a una despersonalización reflejada en normativas que ponían énfasis en homologar a la población carcelaria por medio de reglamentos y de un uniforme de un saco y un pantalón de reclusos, algo que la propia Ley Penitenciaria Nacional, que estipulaba reglas más humanizadas para el tratamiento de los reclusos, consideraba humillante. Asimismo, la distancia de los grandes centros urbanos, lugares de donde provenía la mayoría de los presos, dificultaba enormemente el contacto con los parientes o con los abogados defensores. Casi todos los familiares que no tenían recursos acudían a las "comisiones de solidaridad" que se gestaron como parte de una fuerte corriente de respaldo en favor de los detenidos. La finalidad en este caso de las comisiones era conseguir dinero para los pasajes en ómnibus y para la estadía en hoteles locales. Sin embargo, esta asistencia no siempre alcanzaba para que todos los que lo deseaban pudiesen visitar a sus seres queridos. ${ }^{8}$ Aquellos/as que sí lograban llegar, debían superar engorrosos trámites, esperas y largos interrogatorios de los penitenciarios.

Además, las normas para el ingreso al penal eran cambiadas de modo arbitrario todo el tiempo. Se les fue exigiendo a los familiares nueva documentación probatoria de los vínculos filiales 
o conyugales. Como algunos familiares no contaban con estos papeles, ya que los tenían en sus provincias de origen, sus viajes se tornaban infructuosos y desmoralizantes. Señala un militante de la organización de extracción marxista, Partido Revolucionario de los Trabajadores y Ejército Revolucionario del Pueblo (PRT-ERP), que fue detenido en septiembre de 1974 y que estuvo confinado en Rawson, que incluso "en algún momento comenzaron a pedirles a nuestros familiares un certificado del hotel donde se alojaban".? Entre estos distintos protagonistas se habían ido tejiendo fuertes lazos de sociabilidad que estimularon un intercambio cada vez más político y conciente de las fuertes condiciones represivas a las que estaban sometidos en la región. Por eso, esta medida se tomó con el doble objetivo de, por un lado, controlar los movimientos de los familiares y, por el otro, vigilar a los pobladores que se habían mostrado preocupados por las urgencias de los presos. Las Fuerzas Armadas temían el resurgir de una organización como la que se había gestado en el levantamiento popular del Trelewazo, donde el pueblo y los familiares de los detenidos se sublevaron, luego de la masacre de agosto, ${ }^{10}$ pidiendo que se esclarezcan los hechos y en repudio a los allanamientos y detenciones realizadas a los activistas lugareños por las fuerzas de seguridad. ${ }^{11}$

También el envío de cartas estaba censurado ya que éstas se abrían, se leían y eran tachadas en sus contenidos "inapropiados" por personal del penal. El no poder conversar casi de ningún tema, ya que todos los asuntos resultaban controversiales y prohibidos, convertía a la carta en un artefacto totalmente formal, por lo que era decisivo lograr una forma cifrada de comunicación, algo que los presos con el tiempo pudieron desarrollar. Durante esta época se vio obstaculizada, además, la posibilidad de ejercitar el derecho de legítima defensa ya que los abogados también eran víctimas de numerosas humillaciones por parte de los agentes penitenciarios.

En el marco de este proceso de gradual subsunción del servicio penitenciario por parte de las fuerzas militares, se puso en marcha la eliminación de las garantías legales, maltratos y humillaciones constantes hacia los presos como instancias de castigo. Así, fueron constituyéndose los pasos previos y necesarios para la producción de los efectos devastadores de la subjetividad en los presos políticos. 


\section{E1 "tratamiento" penitenciario durante el Estado terrorista}

Indudablemente desde el año 1974 el sistema aplicó gradualmente procedimientos y reglamentos más severos. La situación se fue deteriorando a medida que los presos y presas fueron puestos a disposición del Poder Ejecutivo Nacional (PEN) ${ }^{12}$ y concentrados en grandes establecimientos provinciales y federales desde el año siguiente, como la Unidad de Devoto para las mujeres y las Unidades de Resistencia, Coronda, Sierra Chica, La Plata y Rawson para los varones. El recrudecimiento se expresó de varias maneras. Una de las formas fue la asignación de pabellones diferenciales respecto de los presos comunes. A su vez, los presos políticos fueron clasificados según grados de responsabilidad militante que resultaban decisivos para el tipo de tratamiento que recibían en la cárcel. Fueron importantes también las nuevas restricciones impuestas a la vida cotidiana a través de los escasos recreos, la imposibilidad de reuniones generales en los pabellones y la discrecionalidad con el acceso de las visitas que terminaron de definir el agravamiento de las condiciones carcelarias. También comenzó a haber una disminución en las raciones alimentarias y dilaciones en las gestiones administrativas que necesitaban los presos para llevar adelante sus trámites judiciales. Se promulgaron, además, ordenanzas y reglamentos internos con el fin de regular y sujetar a los cuerpos apresados a los más mínimos e innumerables detalles.

Aun con las limitaciones que aquí detallamos, para mediados de 1975, ya en el conflictivo gobierno de la viuda del general Perón, María Estela Martínez de Perón, el sistema penitenciario deteriorará todavía aun más las condiciones de vida carcelaria de los presos políticos, ya que comenzaron a ser frecuentes las amenazas, las brutales requisas y los golpes. Además, las fuerzas militares, en complicidad con las penitenciarias, practicaban con regularidad secuestros nocturnos de los presos políticos a localidades cercanas, a veces, a una comisaría o a algún otro predio de las fuerzas de seguridad. Los presos eran obligados a viajar con los ojos vendados para impedir el reconocimiento de sus captores, eran golpeados y 
pateados dentro de los vehículos e incluso en oportunidades eran sometidos a simulacros de fusilamiento. ${ }^{13}$

A dos meses del golpe de 1976, el penal patagónico había colmado su capacidad instalada, alcanzando los presos políticos un número superior al de los 300 . Este aspecto se entrelaza con el hecho de que para esta época, el personal penitenciario, entre celadores y personal de mayor jerarquía, se había incrementado fuertemente respecto de años anteriores, lo que determinaba la existencia de dos penitenciarios por cada preso político, haciendo ostensible el carácter violento y de máxima seguridad del penal (SAMOJEDNY, 1986, p. 565).

Asimismo los militares comenzaron a premiar a los penitenciarios a modo individual y a jerarquizarlos como fuerzas de combate. Este es uno de los motivos por los que surgieron líderes de la lucha contra la "subversión" dentro del penal. Otra cuestión fuertemente vinculada con la militarización penitenciaria es la sustitución en su escudo de la balanza de la justicia por una torre cruzada por dos fusiles, poniendo de manifiesto a nivel simbólico las transformaciones del aparato represivo.

El comienzo de la última dictadura militar en Argentina hacia marzo de 1976, profundizó la debilidad de las instituciones estatales que fueron progresivamente controladas por las fuerzas armadas. La cárcel de Rawson no fue una excepción a esta tendencia. A partir del comienzo de este nuevo período histórico, fue colocada bajo la autoridad directa del área del V Cuerpo de Ejército, lo que significó que el penal pasó a formar parte de la red represiva del área de este comando, contribuyendo con el secuestro de presos que circulaban entre este penal y otros espacios clandestinos de detención como comisarías, cuarteles y delegaciones de la Policía Federal. ${ }^{14}$

La concentración de poder en las cárceles en manos de las fuerzas armadas, no fue un mero cambio administrativo: por el contrario, tuvo consecuencias directas sobre la vida cotidiana de los presos políticos. Las nuevas técnicas de dominio fueron implementadas por una estructura militar que emitía órdenes, algunas de ellas secretas. Sin embargo, el personal penitenciario que incluía a los carceleros, los médicos o enfermeros se encuadraba en directivas y normas emitidas a nivel nacional por el Servicio Penitenciario Federal. Sin bien éstas 
eran confluyentes con las políticas de disciplinamiento más general del régimen, en oportunidades colisionaban con las disposiciones confidenciales. ${ }^{15}$ Por ejemplo, en los reglamentos, muchas veces desconocidos por los propios internos, tampoco estaba escrito que cualquier "falta" podía implicar golpizas, encierros prolongados en espacios sin aire y luz o la permanencia de internos desnudos y de pie por horas frente a sus celdas a muy bajas temperaturas. Los penitenciarios desarrollaban el vínculo con los presos políticos en una tensión entre prácticas represivas que estaban previstas en los reglamentos y otras, como los secuestros que no formaban parte de una normativa legal. El tratamiento penitenciario durante esta etapa estuvo condicionado entonces por el carácter oculto que tuvo la represión para la sociedad civil.

La tentativa de deteriorar la subjetividad de los presos políticos se vio reforzada por la incorporación de distintas ramas del penal a este propósito. Mientras los médicos y los enfermeros se negaban a ofrecer tratamientos de curación o de seguimiento de padecimientos crónicos, el área de recepción de visitas ponía todo tipo de obstáculos para el ingreso de los familiares al penal. Por otro lado, los capellanes inducían a los presos a la culpa y al arrepentimiento de su militancia, cumpliendo incluso en numerosas oportunidades roles de inteligencia con el fin de obtener información sobre las discusiones que llevaban adelante los presos en Rawson. También el área de legales dentro del penal perturbó la confección y/o envío de recursos de amparo o de hábeas corpus, y muchas veces imposibilitó a los detenidos políticos los pocos vínculos que podían desarrollar con sus abogados defensores. La proveeduría restringió el ingreso de alimentos que contribuyeran con un mejoramiento de la dieta hipocalórica suministrada por el penal. El sector de penitenciarios que realizaba la requisa, preparado para tareas de intimidación, asestó cotidianamente insultos, amenazas y palizas. Rubén Bustos declaró en la causa $\mathrm{N}^{\circ}$ 500/80, que cuando estuvo detenido en Rawson a esta formación especial se la conocía como "Pelotón Fantasma", aludiendo a su carácter temerario y brutal. ${ }^{16}$

Esta intensificación de la represión en el penal estuvo en sintonía con lo que ocurría en la vida política del país. En los dos primeros años del gobierno de facto se produjeron la mayor cantidad 
de desapariciones forzadas. Asimismo fue el momento de gran concentración de presos políticos. A pesar de que la represión se incrementaba en uno y otro ámbito, los militares intentaron subrayar la diferencia entre el adentro y el afuera de manera cada vez más clara, incrementando la cantidad de rejas con el objetivo de amedrentar y también de reducir las posibilidades de fuga de los presos vulnerando la seguridad interior. Los calabozos de castigo se cuadruplicaron durante este período pues los internos recibían sanciones permanentemente. Eran unos habitáculos de 0,80 de ancho por 2 de largo y 4 metros de alto. Sin baño ni bacinilla, mientras estaban en el calabozo, debían usar su propia celda como depósito de sus evacuaciones. Casi no entraban luz ni aire por el ventanuco en alto, casi siempre tapiado, con un piso de color negro y paredes grises. El frío, la imposibilidad de sentarse y de descansar, transformaban todo el espacio en monótono y sin texturas, y producía en los presos, luego de semanas de encierro, un fuerte debilitamiento físico al que se le iban sumando notables alteraciones de la percepción.

La estrategia de desgaste psicológico se asentó fuertemente en la alternancia entre carceleros que pretendían jugar roles alternativos entre "buenos" y "malos" para engañar y vulnerar la confianza de los detenidos y la resistencia a sus políticas represivas.

Sin embargo, durante 1977 los militares fueron concientes de que su intento de romper la subjetividad de los presos políticos no tenía el efecto positivo que ellos habían previsto, pues los reclusos resultaban ser en términos generales, indoblegables en sus convicciones ideológicas. Este diagnóstico, expresado además en un documento de carácter secreto, ponía en evidencia la necesidad que tenían los militares de reducir al máximo el número de detenidos caracterizados como "irrecuperables". ${ }^{17}$ Se debía quebrar a los presos políticos con el fin de evitar que las cárceles se convirtiesen en centros de adoctrinamiento. El documento dejaba abierta la posibilidad de aplicar una batería de torturas físicas, psíquicas y morales para forzar a los presos políticos a que abandonasen toda tentativa de pensarse de modo autónomo. Incluso, la resolución secreta era planteada como una contribución al combate de cada uno de los eslabones que formaban la cadena de la delincuencia "subversiva". Esta disposición nos permite comprender que el "tratamiento" para 
los presos políticos se modificaba en función de las necesidades y diagnósticos de la situación que los militares y penitenciarios hacían sobre esta población.

\section{La desubjetivación como desmasculinización}

Creemos que el proceso de desubjetivación que se ensayó contra los presos políticos, se montó sobre las características centrales del sistema de sexo-género, que operó de modo diferente para varones y para mujeres. Por lo que una comprensión cabal del intento de vulnerar la subjetividad que los militares llevaron a cabo requiere de un análisis de género.

La dominación sexual no fue reglamentada. Tampoco formó parte de los decretos secretos. Sin embargo, de modo "oculto" fue constituyente y estuvo en concordancia con la lógica de otras prácticas represivas. Por ejemplo, en relación a las presas políticas concentradas en la cárcel metropolitana de Villa Devoto de la ciudad de Buenos Aires, se intentaron distintas estrategias para desmantelar la subjetividad. Con aquellas que eran madres se tuvo por propósito socavar su maternidad; primero quitándoles a sus niños de las celdas y dándoselos en guarda a las familias de origen en caso de que hubiese. Sin embargo, cuando no había familiares que pudieran cuidar de los niños se promovían mecanismos de adopción contra la voluntad materna. Otra forma de esta política fue privar a las presas del trabajo manual, incluso aquel atribuido como propio y "natural" del género femenino, como la confección de prendas o en la cocina del penal. ${ }^{18}$

En el caso de los varones presos en el penal de Rawson la forma que adquirió la dominación a través del eje sexual tuvo una estrategia metódica. Analizándola podemos observar una tecnología que apuntaba a la desestructuración de los rasgos básicos asociados regularmente con la masculinidad. Para comprender sus efectos devastadores, vamos a servirnos del concepto de encerrona trágica del psicoanalista Fernando Ulloa. Este autor define la encerrona trágica como una particular situación en la que hay sólo dos lugares 
en juego, el de la víctima y el victimario, sin un tercero de apelación, lo que él denomina el tercero de la ley.

Si la subjetividad es el anudamiento de distintos aspectos y registros, simbólicos, imaginarios, públicos, íntimos y privados, podremos observar que la anulación del tercero de la ley, redundó en la disminución gradual de las garantías legales como así también constituyó una etapa que podríamos considerar preparatoria de lo que posteriormente se consolidará en un avasallamiento y sujeción de las identidades de género y sexuales. La anulación del otro mediador se manifestó en: 1) imposibilidad del ejercicio mínimo de derechos de un proceso penal quedando a merced del capricho del otro, 2) falta de autonomía para desarrollar acciones de acuerdo a gustos, creencias y necesidades tales como hacer gimnasia, realizar lecturas o escribir cartas, entre otras posibilidades, 3) impedimento de socializar sin estar sometido a un aislamiento que debilite la integridad física y psicológica incluyendo en ella las cuestiones más elementales como alojamiento, higiene y atención médica, 4) la coacción al ejercicio de prácticas sexuales y de género. Estas categorías que acá se presentan analíticamente por separado en la realidad se encuentran profusamente entremezcladas.

En los siguientes apartados proponemos una interpretación de tres aspectos en los que observamos la desmasculinización (considerando previamente que la desubjetivación es, siguiendo una lectura desde el psicoanálisis, un aplanamiento del sujeto y su objetalización): la devastación del cuerpo, la negación de la sociabilidad masculina y la sexualización de la tortura.

\section{La devastación del cuerpo}

La desmasculinización sirvió para los intentos de devastar físicamente a los presos políticos. Valeria Manzano (2010) quien ha investigado a los jóvenes como actores culturales y políticos en la Argentina demediados del siglo XX, desarrolla el concepto de "cuerpos incansables" que alude a la sobre valoración que tenían de sí mismos los militantes de las organizaciones revolucionarias 
en torno a la estructuración de la práctica política centrada en las destrezas físicas, a lo que se le sumaba el entrenamiento de tipo militar, de fuerza y resistencia. Esta exigencia incluso exhortaba a la militancia a mantener una abstinencia con respecto del uso de drogas, sea social o experimental, con el fin de estar siempre alertas frente al enemigo.

En este sentido un cuerpo preciso y su representación, eran resultado para esta generación de militantes, parafraseando a Elizabeth Grosz, de una "experiencia vivida corpóreamente". ${ }^{19}$ La perspectiva del "hombre nuevo" propuesta por Ernesto "Che" Guevara, y que la militancia revolucionaria tomó en su conjunto como un modelo a seguir, construía una subjetividad política atravesada fuertemente por estándares masculinos centrados en las nociones de resistencia y coraje complementados con las ideas de rudeza y dominio. ${ }^{20}$ Si bien por entonces la noción de "hombre" se pretendía como universal y no generizada, en la práctica no implicaba sujetos abstractos sino varones con cuerpos y fisonomías particulares.

A pesar de las diferencias ideológicas que separan a unos de otros, la masculinidad del activismo de este período se asemejaba a aquella promovida por las fuerzas militares, quienes también fundaban el estatus de varón en la destreza física y la resistencia corporal. Cuando los militares perfilaron el modo de quebrar el espíritu de lucha de los presos políticos, vislumbraron vulnerar la integridad de los varones, desmasculinizándolos ${ }^{21}$

El 30 de mayo de 1980, en un momento en el que la represión se había morigerado, en parte por la visita a las cárceles de la Comisión Interamericana de Derechos Humanos (CIDH), Carlos Kunkel, preso político, confeccionó un recurso de amparo solicitando que se lo mudara a un penal menos hostil que el patagónico. En ese escrito Kunkel, colocaba en un lugar central sus reclamos por las múltiples restricciones que los presos políticos tenían para realizar ejercicios físicos, ya que "ni durante el horario de recreación en el patio ni en el pabellón, estaba permitido hacer movimientos gimnásticos, siendo pasible de sanción cualquier gesto al que se le atribuya ese carácter". 22 Dicho reclamo expresaba la imposición del régimen carcelario de permanecer dentro de las celdas, sin más que estar recostados en sus camastros durante casi todo el día, 
provocándoles a algunos entumecimientos, inflamaciones o edemas en los miembros inferiores.

Por otro lado, observando la alimentación suministrada por el penal, según relata Joel Geoninatti, detenido en Rawson desde mediados de 1977, les "entregaban unas 450 calorías [...] por día."23 Se trataba de raciones mínimas para que los internos no sucumbieran y, a la vez, para obligar al cuerpo a consumir al máximo las reservas, quedando los detenidos sólo con piel y hueso. ${ }^{24}$

La alimentación deficitaria produjo efectos a corto, mediano y largo plazo. Si en un principio esta insuficiencia redundó en una disminución notable del peso corporal y de la masa muscular por carencia de vitaminas, proteínas y minerales, en otra fase posterior, derivó en cuadros de desnutrición y en trastornos hormonales, tales como la caída del vello.

Además, la escasa o casi nula atención médica agravaba aún más los efectos sobre los cuerpos. Los médicos solían confeccionar un diagnóstico a distancia, puesto que por cuestiones de "seguridad" no ingresaban a las celdas. Los enfermos crónicos, asmáticos o cardíacos, tenían prohibido contar con sus medicamentos, lo que llevaba al desencadenamiento de importantes descompensaciones.

Este abuso de poder por parte de los médicos, además de violar el juramento hipocrático, colocaba al interno que necesitaba de su medicación, en una posición que, una vez más, grafica aquel concepto de encerrona trágica, donde la víctima para curarse debe someterse al capricho de su victimario.

Además de estas políticas sobre los cuerpos, hubo otras prácticas cuyos efectos se inscribieron en lo que llamaremos lo mental, y que en esta oportunidad fueron llevadas adelante por una de las especialidades del saber médico como es la psiquiatría. Lo importante para destacar es que la terapéutica implementada por este sector se centró en la utilización profusa de psicofármacos. Así, ciertas alteraciones, tan comunes tanto dentro como fuera de una cárcel, como son las fallas en la percepción producidas por prolongados encierros a oscuras; la depresión; la ansiedad; el insomnio o las palpitaciones fueron tratadas exclusivamente por medio de potentes narcóticos.

Además señala Carlos Samojedny en su declaratoria, que la misión de uno de los médicos del penal, el Dr. Barck, se reducía a 
experimentar con psicofármacos entre los internos, especialmente con la droga que estaba de moda en los años setenta con el nombre comercial de Valium (depresor del SNC). Explica también Samojedny ${ }^{25}$ que "'planchaban' al interno o lo dormían como una seda [...] Al interno Schalier que era un depresivo, le daban un depresivo, en lugar de darle un antidepresivo, lo que lo aplastaba más y dormía y dormía". ${ }^{26}$

En las cárceles de este período se recurrió a las modernas prácticas y al saber de la medicina psiquiátrica, la psicología e incluso, en oportunidades, la sociología, para incidir fuertemente en el proceso de desubjetivación.

\section{La sexualización de la tortura}

Según testimonios que dieron los presos políticos en distintas oportunidades, entre febrero de 1977 y julio de 1978 se aplicó la mayor cantidad de torturas físicas, coincidente como ya dijimos, con la fuerte represión practicada contra toda la sociedad. La golpiza era un tormento que tenía como objetivo quebrar física y moralmente a los militantes con el fin de convertirlos "en seres atemorizados, recelosos y dóciles por efecto del terror". ${ }^{27}$ Ariel Asuad relata cómo fue su ingreso al penal como detenido y cómo lo recibió y lo trató uno de los médicos que lo atendió.

Junto a éste se encontraba un nutrido grupo de oficiales del Servicio Penitenciario Nacional y de la Marina de Guerra, uniformes que identifica perfectamente. Que en razón de haber llegado desmayado y arrastrado, fue tomado como ejemplo de la efectividad del procedimiento por el facultativo, quien le ordenó se desvistiese y pusiese los brazos en alto contra una pared de la celda, mostrando al grupo de oficiales la señal evidente de los golpes que el declarante había sufrido en la espalda, la que se encontraba llena de protuberancias e hinchazones. ${ }^{28}$ 
Este testimonio pone de manifiesto el modo en el que un núcleo de varones empoderados gozaba con la humillación de otro grupo de varones subordinados por medio de una vinculación sádica a través de la exhibición del cuerpo lastimado, y también, hasta qué punto el ataque a la corporalidad que implicaba desmasculinizar, yace en el modo en que se practicaba la tortura. En este sentido, no se trata entonces tan sólo de que la cárcel privó a los varones de su fuerza física y su raciocinio, que son, no obstante, claros símbolos de masculinidad, sino que cuando se desplegaba la tortura física se la dirigía a la zona del cuerpo que en nuestra cultura resulta fundante de la masculinidad misma y que son los genitales. Siguiendo un relato de un detenido político sobre este punto, se señala que:

Nos tenían desnudos, de espaldas sobre los pasillos, prohi-
biéndonos mirarnos, y se nos preguntaba sobre la actividad
que desarrollábamos afuera, sindicatos, partidos políticos,
etc. Nos golpeaban con bastones de goma, con núcleos de
acero. Como rúbrica, elegían uno al azar y le daban sesiones
más prolongadas de golpes que producían hematomas en
los genitales. ${ }^{29}$

Con bastones de goma y manoplas de acero golpeaban directamente en los órganos sexuales y reproductores y se ocupaban de ultrajar "lo masculino". Incluso cuando las torturas no apuntaron directamente al aparato genital, seguían teniendo por objeto lugares del cuerpo que connotan peculiaridades masculinas. Ejemplo de ello es el testimonio de Eduardo P, cuando el 12 de noviembre de 1984, contó ante personal del Poder Judicial, que luego de haber sido trasladado con los ojos vendados y las manos atadas en un avión, "cuando llegó lo patearon, con golpes de puño y a tirones le arrancaron los bigotes". Este último gesto debe ser interpretado como un intento singular de borramiento de las características viriles más elementales como lo es la existencia de bigotes. ${ }^{30}$

En el caso de Eduardo P, los penitenciarios redoblaron la apuesta cuando luego de hacerlo desnudar "con un pedazo de palo de escoba se lo introdujeron en el ano, no sólo a él sino también a otros detenidos". ${ }^{31}$ La violación y la dominación adquiría un carácter 
sexual, y resultó un rito de ingreso al penal de Rawson. Los ingresantes eran desnudados, podían hacerlos correr por los pabellones y, en oportunidades, incluso debían hacerlo encadenados. Luego eran sometidos a una revisación de los genitales y del ano, por personal penitenciario, sea este médico o del sector requisa. Esta metodología, convertía el ingreso en un acto brutal en sí mismo y un modo de marcar los límites entre el afuera y el adentro carcelario. De este modo, la institución penitenciaria intervenía en esa primera instancia de recepción con gran fuerza simbólica, delimitando una economía distributiva del poder sexual. La primera intromisión en el cuerpo masculino resulta de una revisación ano-genital que provoca la sujeción allí donde "el polo jerárquico se constituye y realiza justamente a expensas de la subordinación del otro" (SEGATO, 2003, p. 31).

Los penitenciarios hurgan en los agujeros de los delincuentes subversivos. El ano se convierte en un lugar oscuro donde se puede guardar información o, en su defecto, desde la perspectiva paranoica de la institución, donde se pueden ocultar incluso municiones o información vital que atente contra el régimen militar.

La teoría de género es particularmente apropiada para comprender por qué la "penetración" de los presos en la tortura por parte del poder penitenciario militar presenta un doble objetivo. Por un lado, es posible proyectar la desmasculinización de la "víctima" a través de la sodomización, mientras los "penitenciarios" se constituyen como sujetos institucionales y como sujetos sexuales. En la dialéctica ya señalada, en los "premios" a los agentes más dinámicos en la lucha contra la "subversión", se delimita también una sexualidad, donde los carceleros compiten por una masculinidad, preservada en calidad de penetrador sexual, que no pone en litigio los modelos sociales heteronormativos. Este acto violatorio en el que se sublima el pene a través de un instrumento fálico como puede ser un palo de escoba, sirve para reafirmar en los penitenciarios la (re) producción de su masculinidad. ${ }^{32}$

Tal como sostiene Mariana Sirimarco, el mandato de violación resulta de una estructura propia de la manufactura de la masculinidad, aunque "no es ni una práctica exclusiva de los hombres ni son únicamente las mujeres las que la padecen. Una violación se perpetra contra quien exhibe significantes femeninos" (SIRIMARCO, 2004, p. 68). 
En este sentido, aquel que se coloca o es colocado en posición femenina, habilita una práctica de violación: el penitenciario "penetra" y la víctima sólo tiene que exhibir, luego, el resultado de tal acto. ${ }^{33}$ El penitenciario a la vez que se potencia en un imaginario de fuerza que le permite sodomizar al más débil, teatraliza su identidad masculina centrándose "en la exhibición de su sexualidad como capacidad viril”" (SIRIMARCO, 2004, p. 67).

La contrapartida de desvirilizar al enemigo, con su correlato en la feminización, tuvo por finalidad entonces, arrancarles a los presos su condición de adversarios políticos.

Sin embargo no todas las acciones de los penitenciarios se enmarcan en esta lógica viril, heteronormativa, penetrante y violatoria. Hay situaciones en las cuales los varones presos son sometidos a una pérdida total de su voluntad y deben actuar como instrumentos de la voluntad incuestionable del carcelero. Orlando C., otro detenido político, testimonió que mientras recibía toda clase de insultos en el penal de Rawson, "se lo obliga a masturbarse, a arrastrarse como un perro por un plato de comida y a participar en la golpiza de otros detenidos". ${ }^{34}$ Carlos Samojedny también señaló que él y otros apresados, mientras estaban castigados en los calabozos, ocultos de la vista de otros internos, debían masturbarse a instancias de las órdenes que les daban a los gritos los carceleros.

El goce del carcelero se presenta como un poder absoluto que puede disponer del cuerpo del otro por la abismal distancia jerárquica. La masculinidad del carcelero no hace eje en la penetración en este caso sino en la pretensión fantasmática del ejercicio de una relación de control total del "otro". Desde la perspectiva del captor, los presos aparecen tan desubjetivados y, por tanto, desmasculinizados, que se los puede incluso forzar a masturbarse sin que eso sea percibido por los penitenciarios como una práctica homoerótica. En esta representación el varón preso ha sido desmasculinizado a tal punto que su sexualidad ya no resulta amenazante.

La búsqueda del debilitamiento y de las condiciones de virilidad del preso contrapuesta con el masculinismo y la fraternidad masculina fomentada por la institución penitenciaria, introduce una dimensión sexual de la contienda. Se cree que si se puede controlar la sexualidad se puede controlar a ese "otro" plenamente. 


\section{Conclusiones}

La mayor parte de la bibliografía académica o testimonial sobre esta etapa de la historia argentina se ha centrado en el análisis de la experiencia de los centros clandestinos de detención (CCD). La mayoría de las investigaciones pusieron la atención en estos espacios porque allí se practicaron las mayores atrocidades sobre los enemigos políticos. Sin embargo, esa particular preocupación mantuvo invisibilizado lo que ocurrió en las cárceles legalizadas sesgando el análisis de la compleja articulación de una estrategia represiva única y estatal que enlazaba lo legal con las actividades clandestinas o ilegales.

En las cárceles, el plan de disciplinamiento fue gradual aunque se manifestó en sintonía con las prácticas de aniquilamiento ejercidas en los CCD. ${ }^{35}$ De hecho, actualmente las densas interconexiones entre los CCD y el sistema penitenciario y la conjunción de ambos mecanismos represivos, están siendo investigadas por el poder judicial en distintas causas de lesa humanidad.

En este marco el penal de Rawson se construyó en los bordes de una cárcel "legal", tanto por su ubicación geográfica en la meseta patagónica, aislado de los grandes centros urbanos, como por la implementación de modernas tecnologías disciplinadoras que pretendían alcanzar la desarticulación ideológica por medio del aislamiento, el maltrato y la violencia física y sexual. Si el plan explícito de los militares y los penitenciarios resultó de la estrategia de desubjetivación política, esta tecnología represiva encarnó en la pretensión de desestructurar la masculinidad por medio de fuertes ataques a la identidad de género y sexual.

Es muy significativo que, si bien no se generalizaron estas prácticas en otros penales ni a todos los presos, por un lado hubo políticas de desexualización como hemos intentado mostrar en este texto, a la par que se promovieron sexualizaciones compulsivas. En tensión, y de modo contradictorio, lo que provee de unidad a unas y a otras es que se enmarcan en la lógica del sistema sexo/género que encuentra permanentemente subjetividades a las que hay que normalizar. ${ }^{36}$ 
No obstante es necesario señalar que si bien hubo una tendencia a la sistematicidad en términos de una lógica de género desmasculinizadora, la represión y el intento de desubjetivación no siguieron una lógica cabalmente planificada. El plan de devastar políticamente a los presos funcionó como la motivación primaria que a la vez se articuló de modo complejo con el sistema de sexo-género, el cual de manera contradictoria llegó a subvertir en oportunidades la matriz de género tradicional y heteronormativa que en el discurso público el régimen militar promovía.

La destrucción ideológica funcionó entonces, como una motivación primaria que se articuló "de hecho" con el sistema de sexo-género normalizador. Los presos opusieron resistencia a cada una de estas políticas por medio de una organización colectiva que politizó al sexo y al género y enfrentó a la autoridad masculina y a sus modalidades de satisfacción sexual. Pero esa es una bella historia que en este texto no podemos contar.

\section{POLITICAL PRISONERS IN RAWSON PENITENTIARY: A TREAT- MENT FOR ARGENTINE DESUBJECTIFICATION (1970-1980)}

Abstract: Rawson Penitentiary, located in the province of Chubut, Patagonia, developed as a unique prison facility within the penitentiary network, were political prisoners were interned during the dictatorships of the sixties and seventies. The technology of discipline applied in Rawson was based on a variety of torments deliberately anti-constitutional and alien to the regulatory framework of the Argentine penitentiary system.

From a gender perspective, this article argues that although the explicit goal of the military regime in breaking prisoners' subjectivity was their ideological and political obliteration, desubjectification was carried out in terms of a demasculinizing gendered logic that contradicted the public rhetoric of masculinity of the military and the penitentiary officials. This reveals the inconsistency between their public, family-centered gender discourse and their disciplining practices in private spaces of internment.

Keywords: Political prisoners. Repression. Desubjectification. Demasculinization. 


\section{Notas}

${ }^{1}$ El desarrollo histórico de los aparatos represivos del Estado nacional entre los años 1966 y 1973, es estudiado por Eidelman (2010)

${ }^{2}$ Ver este aspecto en Rubano (1994)

${ }^{3}$ Algunas perspectivas producidas en las últimas dos décadas sobre este tema se encuentran en Pión-Berlin (1989), Carlson (2000), Leal Buitrago (2002), Llumá (2002), Robin (2005), Franco (2009) y Ranalletti (2009).

${ }^{4}$ Una historia del castigo administrado por el Estado moderno y la reforma del delincuente se puede consultar en Caimari (2004).

${ }^{5}$ Ver Servicio Penitenciario Federal http://www.spf.gov.ar, sección penal de Rawson.

${ }^{6}$ Foro de Buenos Aires por la Vigencia de los Derechos Humanos (1973: 89).

${ }^{7}$ Por medio del decreto ley N. 412 del 14 de enero de 1958, ratificado posteriormente por el Congreso de la Nación mediante la Ley 14.467, se sancionó la Ley Penitenciaria Nacional, complementaria del Código Penal.

${ }^{8}$ En Trelew se creó en septiembre de 1971, a pocos meses de que la cárcel fuera convertida en una prisión de máxima seguridad, una comisión de solidaridad en apoyo a los presos políticos. Esta comisión se constituyó no sólo como una entidad de apoyo a los prisioneros, sino también como corriente de clara oposición a las políticas represivas de la dictadura del general Lanusse.

${ }^{9}$ Entrevista de la autora a Julio M, agosto de 2008, Buenos Aires.

${ }^{10} \mathrm{El} 15$ de agosto de 1972, tras meses de una minuciosa preparación, se fugaron del penal de Rawson numerosos miembros de las organizaciones armadas del Ejército Revolucionario del Pueblo (ERP), de las Fuerzas Armadas Revolucionarias (FAR) y de Montoneros. Por fallas operativas en el apoyo externo previsto para el escape, solo seis de ellos, los cuadros más importantes, lograron evadirse. Un segundo grupo integrado por diecinueve guerrilleros al ver imposibilitada la fuga tuvieron que entregarse siendo trasladados a una base militar, encerrados en celdas individuales y torturados psíquica y físicamente durante una semana. En la madrugada del 22 de agosto fueron sacados de sus celdas y sometidos imprevistamente por más de veinte minutos al fuego de las ametralladoras. Sólo tres sobrevivieron. Sus testimonios fueron fundamentales para reconstruir lo sucedido en la base militar aquella noche. Ver este tema en Petralito y Alderete (2007) y Cherén (2007).

${ }^{11}$ Véase sobre este levantamiento regional, La Pasión según Trelew de Tomás Eloy Martínez (2007, [1973]) que relata el levantamiento del pueblo de Trelew. Esta novela fue publicada por primera vez en 1973, prohibida a fines de ese mismo año y posteriormente quemada en una guarnición militar. La edición del 2007 fue 
corregida y ampliada por el mismo autor. También consultar las investigaciones de Ramírez (2006) y González Canosa (2011).

${ }^{12}$ Los presos y presas quedan a disposición del Poder Ejecutivo Nacional (PEN) en el marco del acrecentamiento de atribuciones del presidente/a de la República tras la declaración del estado de sitio, lo que le permite arrestar o trasladar a las personas de un punto a otro del país sin facultades para aplicar penas. Desarrolla este tema en profundidad el jurista, Bidart Campos (1977)

${ }^{13}$ Ramón Torres Molina, abogado y militante peronista, en su declaración en la causa N. $^{\circ}$ 500/80 relató su secuestro del penal de Rawson por fuerzas militares y su trasladado a la ciudad de Comodoro Rivadavia en un vuelo de una aerolínea comercial para ser torturado. Ver detalles sobre origen de la Causa N. ${ }^{\circ} 500 / 80$ (obrante en el Archivo Nacional de la Memoria, en proceso de catalogación). La causa $N^{\circ} 500 / 107 / 80$ lleva por nombre "Sobre apremios y torturas en la Unidad N 6 de la localidad de Rawson" y fue agregada al expediente "Steding Jorge Osvaldo y Govi Ramon Miguel, infracción artículo 144 bis y 142 del CP”. Esta documentación judicial remite al cuerpo principal del expediente judicial que consta de 30 cuerpos con más de 11 mil fojas, donde se relatan a través de 260 declaraciones, las violaciones a los derechos humanos sucedidas en el penal durante la última dictadura militar. A partir de los testimonios y la pesquisa judicial se comenzó a reconstruir la estructura represiva de la región, la cadena de mandos del V Cuerpo del Ejército con asiento en Bahía Blanca, así como a identificar a los centros clandestinos zonales. En la causa se adjuntan diversas comunicaciones entre las fuerzas armadas y las fuerzas penitenciarias a través de memos, telegramas, tráficos de radio, radiogramas, formularios diversos de pedidos de informes y contra informes que ponen en evidencia la estrecha relación de unos y otros y el rol del sistema penitenciario como pieza clave del accionar represivo. ${ }^{14}$ El V Cuerpo de Ejército se ocupaba de administrar el plan represivo en las provincias de Neuquén, Río Negro, Chubut y Santa Cruz y algunas localidades de la provincia de Buenos Aires, entre ellos la ciudad de Bahía Blanca.

${ }^{15}$ Este fue el caso de los decretos N. ${ }^{\circ} 955 / 76$, N. $^{\circ} 780 / 1979$ o N. ${ }^{\circ} 929 / 80$, instancias normativas regulatorias de numerosos aspectos de las personas privadas de su libertad por motivos políticos.

${ }^{16}$ Causa N. ${ }^{\circ}$ 500/80 sobre apremios y torturas en el Penal U6 de Rawson. Ver fojas 1092 y 1093 .

${ }^{17}$ Disposición secreta del año 1977, llamada "Recuperación de Pensionistas". Ver ANM.

${ }^{18}$ Ver un análisis sobre las políticas penitenciarias de desestructuración de género y sexual en las presas políticas de Villa Devoto en D’Antonio (2009, 2011). 
${ }^{19}$ Grosz ha explicado que la confluencia del feminismo y las teorías de género, por un lado, con el psicoanálisis por el otro, han permitido resignificar al cuerpo como un producto psicosocial (Grosz, 1992).

${ }^{20}$ Ver la semblanza que se publica en una publicación del Frente Antiimperialista por el Socialismo (FAS) sobre Luis Pujals, segundo jefe político del ERP que fue secuestrado, torturado y asesinado por el Comando del II Cuerpo de Ejército, donde se ratifican los valores de abnegación y sacrificio, en Nuevo Hombre, N. $^{\circ}$ 23, 12 de diciembre de 1971 relevado en Manzano (2010).

${ }^{21}$ Para un análisis sobre la constitución del sujeto masculino policial en términos de género, ver Sirimarco (2004).

${ }^{22}$ Causa N. ${ }^{\circ} 500 / 80$ sobre apremios y torturas en el Penal U6 de Rawson. Expediente N. ${ }^{\circ}$ 500/107/1980. Sin fojas, ver carta inicial de Carlos Kunkel al juez Omar Garzonio.

${ }^{23}$ Causa N. ${ }^{\circ}$ 500/80 sobre apremios y torturas en el Penal U6 de Rawson. Ver fojas 1938 y ss.

${ }^{24}$ Es importante destacar que adicionalmente el reglamento prohibía todo ingreso de alimentos enviados por familiares y los internos solo podían consumir algunos de una lista muy reducida de la proveeduría del penal, los que por otro lado, se compraban a precios muy elevados. De este modo no solo no se proporcionaban raciones de comida razonablemente nutritivas sino que no se permitía que los familiares contribuyeran con la alimentación..

${ }^{25}$ Carlos Samojedny, psicólogo y también militante del PRT-ERP, estuvo preso en el penal de Rawson por más de una década.

${ }^{26}$ Causa N. ${ }^{\circ}$ 500/80 sobre apremios y torturas en el Penal U6 de Rawson. Ver fojas 4424 y ss.

${ }^{27}$ Extraído de www.pparg.org.

${ }^{28}$ Causa N. ${ }^{\circ}$ 500/80 sobre apremios y torturas en el Penal U6 de Rawson. Ver fojas 1050 y 1051 .

${ }^{29}$ Extraído de www.pparg.org.

${ }^{30}$ En diversas culturas y a lo largo de la historia la existencia de vello facial en el rostro de varones maduros se ha emparentado con la posesión de sabiduría o con la potencia sexual. Recién a mediados del siglo XX, se ha asociado la barba, por ejemplo, con la falta de higiene o con la excentricidad.

${ }^{31}$ Causa N. ${ }^{\circ}$ 500/80 sobre apremios y torturas en el Penal U6 de Rawson. Ver fojas 2954 y ss.

32 Para Rita Segato la violación es parte de la estructura elemental de la violencia de género y sexual (2003).

${ }^{33}$ Este es el caso del testimoniante Eduardo P, quien en su declaratoria le muestra a los médicos forenses, una manchas a los costados de los testículos producidas en las sesiones de picana eléctrica que le fueran aplicadas durante su detención. 


\section{Débora D’Antônio}

Ver Causa N. ${ }^{\circ} 500 / 80$ sobre apremios y torturas en el Penal U6 de Rawson. Ver fojas 2954 y ss.

${ }^{34}$ Causa N. ${ }^{\circ}$ 500/80 sobre apremios y torturas en el Penal U6 de Rawson. Ver fojas 1080 y 1081 .

35 Pilar Calveiro (2007) caracteriza la relación entre las cárceles y los campos clandestinos de detención como un continuum represivo.

${ }^{36}$ A modo de un ejercicio comparado, creemos pertinente recuperar el análisis que realiza Gabriel Giorgi en su obra Sueños de exterminio. Allí, el autor sobre la base de la lectura de un corpus literario que recorre algunos textos claves de Ricardo Piglia, David Viñas, Adolfo Bioy Casares, Rodolfo Fogwill y Néstor Perlongher, deconstruye la figuración de la homosexualidad en tanto ésta se constituye como una particular amenaza del cuerpo social. Explica Giorgi que la heteronormatividad se presenta en esta literatura como "natural" y que actúa como una "ficción normativa". Esta esta ficción la que a lo largo del siglo XX, colocó a los homosexuales, a la homosexualidad y a las prácticas homosexuales como un otro manifiestamente deformado y "monstruoso". Ver Giorgi (2004).

\section{Referencias}

ARCHETTI, Eduardo. Masculinidades múltiples. In: BALDERSTON, Daniel; GUY, Donna. (Comp.). Sexo y sexualidades en América Latina. Buenos Aires: Paidós, 1998. p. 291-312.

BIDART CAMPOS, Germán. De nuevo sobre hábeas corpus y estado de sitio. In: El Derecho, n. 36, Buenos Aires, 1977. p. 36-58.

CAIMARI, Lila. Apenas un delincuente. Crimen, castigo y cultura en la Argentina, 1880 1955. Buenos Aires: Siglo XXI, 2004.

CALVEIRO, Pilar. Prólogo. In: GARAÑO, Santiago; PERTOT, Werner. DetenidosAparecidos. Presas y presos politicos desde Trelew a la dictadura. Buenos Aires: Biblos, 2007.

CARLSON, Eric. The Influence of French "Revolutionary War" Ideology on the Use of Torture in Argentina's "Dirty War". In: Human Rights Review, n. 4, 2000. p. 71-84.

CAUSA N $500 / 80$, obrante en el Archivo Nacional de la Memoria en proceso de catalogación.

CHAMA, Mauricio. Movilización y politización: abogados de Buenos Aires entre 1968 y 1973. In. PEROTIN-DUMON, Anne. (DIR.). Historizar el pasado vivo en 
América Latina. Libro electrónico, 2007. Disponível em: <http:/ /www.historizarelpasadovivo.cl>. Acceso en: 10 jul. 2011.

CHEREN, Liliana. La masacre de Trelew. 22 de agosto de 1972. Buenos Aires: Corregidor, 1997.

D’ANTONIO, Débora. Políticas de desarticulación de la subjetividad sexual y de género practicada en la cárcel de Villa Devoto durante la última dictadura militar argentina (1976-1983). Revista Estudios del Centro de Estudios Avanzados de la Universidad Nacional de Córdoba, n. 25, p.159-174, 2011.

Rejas, gritos, cadenas, ruidos, ollas. La agencia política en las cárceles del Estado terrorista en Argentina, 1974-1983. In: ANDUJAR, Andrea; D’ANTONIO, Débora; GRAMMÁTICO, Karin; GIL LOZANO, Fernanda; ROSA, María Laura (Co-comp.). De minifaldas, militancias y revoluciones. Exploraciones sobre los 70 en la Argentina. Buenos Aires: Ediciones Luxemburg, 2009. p. 89-108.

DECRETOS del Poder Ejecutivo Nacional: No 955/76, No 780/1979 o $\mathrm{N}^{\circ}$ 929/80, obrantes en el Archivo Nacional de la Memoria

EIDELMAN, Ariel. El desarrollo de los aparatos represivos del Estado argentino durante la "Revolución Argentina", 1966-1973. Tesis (Doctorado en Historia)- Facultad de Filosofía y Letras, Universidad de Buenos Aires, 2010.

ENTREVISTA a Julio M. Buenos Aires, ago. 2008.

FORO DE BUENOS AIRES POR LA VIGENCIA DE LOS DERECHOS HUMANOS (1973). Proceso a la explotación y la represión en la argentina. Buenos Aires, s/ed.

FRANCO, Marina. La "seguridad nacional" como política estatal en la Argentina de los años setenta. Antíteses, n. 4, UEL, Paraná, p. 857-885, 2009.

GIORGI, Gabriel. Sueños de exterminio. Homosexualidady representación en la literatura argentina contemporánea. Buenos Aires: Beatriz Viterbo, 2004.

GONZALEZ CANOSA, Mora. Las puebladas de principios de los '70, un estudio de caso. Movilización y protesta social en Trelew: la 'Asamblea del pueblo' (octubre 1972)", Tesis (Licenciatura en Sociología) - Universidad Nacional de la Plata, Buenos Aires, 2011, disponible en: http://www.memoria.fahce.unlp.edu. ar/tesis/te.538/te.538.pdf, acceso 3 de septiembre de 2012

GROSZ, Elizabeth. The Body. In: WRIGHT. E. (ED.) Feminism and Psychoanalysis. A Critical Dictionary. Blackwell: Oxford, p. 35-40, 1992.

< http://www.spf.gov.ar, sección penal de Rawson>. Acceso en: 30 oct. 2011.

<http://www.pparg.org>. Acceso en: 16 jul. 2011

Anos 90, Porto Alegre, v. 19, n. 35, p. 141-168, jul. 2012 
LEAL BUITRAGO, Francisco. La Seguridad Nacional a la deriva. Del Frente Nacional a la posguerra fría. Alfaomega Editores: Universidad de los Andes, Flacso-sede Ecuador, 2002

LEY PENITENCIARIA NACIONAL: No 14.467. Disponible en: <http:// www.spf.gov.ar>. Acceso en: 23 nov. 2011

MANZANO, Valeria. Cuerpos incansables: activismo, género y generación entre la militancia revolucionaria argentina de los tempranos setenta. In: III Jornadas Historia, Género y Politica. Buenos Aires: Museo Roca, 2010.

MARTINEZ, Tomás Eloy. La pasión según Trelew. Buenos Aires: Punto de Lectura, [1973], 2007.

ORDEN ESPECIAL N. . 13/77, julio 1977: “Campaña: Recuperación de Pensionistas" Leyes y decretos nacionales referentes a los "detenidos especiales", "DS" ("Delincuentes Subversivos"), "DT" ("Delincuentes Terroristas"), detenidos a disposición del PEN, obrantes en el Archivo Nacional de la Memoria en proceso de catalogación.

PETRALITO, Christian; ALDERETE, Alberto. Trelew. Historia de una masacre y la organización popular como respuesta. Buenos Aires: Nuestra América, 2007.

PION-BERLIN, David. Latin American National Security Doctrines: Hard and Softline Themes. Armed Forces \& Society, v. 15, n. 3, p. 411-430, 1989.

PORTANTIERO, Juan Carlos. Economía y política en la crisis argentina: 19581973. Revista Mexicana de Sociologia, n. 2, p. 531-565, 1977.

RAMIREZ, Ana Julia. Las mediaciones locales de la protesta. El caso del Trelewazo (octubre de 1972). Cuadernos del CISH, n. 19-20, p. 47-80, 2006.

RANALETTI, Mario. Contrainsurgencia, catolicismo intransigente y extremismo de derecha en la formación militar argentina. Influencias francesas en los orígenes del terrorismo de Estado. In: FEIRSTEIN, Daniel (Comp.). Terrorismo de Estado y genocidio en América Latina. Buenos Aires: Prometeo, 2009.

ROBIN, Marie Monique. Escuadrones de la muerte. La escuela francesa. Buenos Aires: Sudamericana, 2005.

RUBANO, María del Carmen. Comunicación y cárcel (1976-1983). Tesis (Licenciatura), Universidad Nacional de Entre Ríos, 1994.

SAMOJEDNY, Carlos. Psicología y dialéctica del represor y reprimido: experiencias de la unidad carcelaria 6, Rawson. Buenos Aires: Rojoblanco, 1986.

SEGATO, Rita. Las estructuras elementales de la violencia. Buenos Aires: Prometeo, 2003. 
SIRIMARCO, Mariana. Marcas de género, cuerpos de poder. Discursos de producción de masculinidad en la conformación del sujeto policial. Cuadernos de Antropología Social, n. 20, Universidad de Buenos Aires, p. 61-78, 2004.

ULLOA, Fernando. Novela clínica psicoanalitica. Historial de una práctica. Buenos Aires: Paidós, 1995. 